instead of in the far recesses of the Cave as is more usual. Their excellent state of preservation suggests that the entrance of the cave must have been blocked by an obstruction for a very long period after the close of the palæolithic age.

\section{Cereals for Spring Sowing}

THE selection of the best varieties of cereals for spring sowing is always a question of importance for the farmer. To meet this need, the National Institute of Agricultural Botany, Cambridge, has issued a leaflet (Farmer's Leaflet, No. 2) describing the varieties most suitable for use in the Midlands, east, and south of England, the recommendations being based on tests carried out at a number of trial stations. The sowing of spring wheat is not, in general, advocated, but of the varieties available, Little Joss is suggested for February and Red Marvel or Al for early March sowings. The choice of oats is, however, much wider. Victory is one of the best all-round varieties, useful both for sale and feeding. Star, an oat similar, on the whole, to Victory, has the additional advantage of a thinner husk and a better standing straw, and is, therefore, preferable on highly fertile soils. Golden Rain and Golden Rain II. also deserve consideration when the crop is intended for feeding on the farm, since the colour of the grain is apt to affect the market price adversely. Marvellous is a further variety which usually gives heavy crops, but it is only suitable for early February sowings. As regards barley, the choice lies between the well-established Plumage and Spratt. Archers and the new variety recently produced by Dr. Beaven, called Golden Archer. The latter is of the Spratt-Archer type, with similar malting quality, but the yield is rather better. For unusually late sowings, the early ripening Victory is suggested as the most suitable. Early sowing of all spring cereals is regarded as of the utmost importanice, irrespective of the variety chosen. In view of the bad harvest conditions of 1931 , farmers are advised to pay special attention to germination. The Official Seed Testing Station, Cambridge, undertakes germination tests at the nominal fee of $6 d$. per sample.

\section{Selection of Sugar Beet Seed}

THE question of the selection of sugar beet seed will soon be receiving the attention of farmers, now that most factories have fixed sugar beet prices for 1932 . The results of the exhaustive trials carried out by the National Institute of Agricultural Botany, Cambridge, in recent years, have been reviewed in the light of the new prices, and it can be confidently said that on most soils the heavy yielding (or E types) will pay the farmer better than the high-sugar-content (or $Z$ ) types. For general cultivation, Kleinwanzleben $\mathrm{E}$ or $\mathrm{N}$, Dippe E, Dobrovice, Hoerning R.R., and Zapotil I can all be recommended; Marsters and Johnston's Perfection should be chosen for early sowing, and on very rich land either of these two or Kuhn P. A Ieaflet describing these strains can be obtained, free of charge, from county organisers, or the Institute, to which application can also be made by those desirous of advice or further information.

No. 3251, VoL. 129]

\section{Forestry in Kenya}

Tre Annual Report of the Kenya Forest Department for the year ending Dec. 31, 1930, affords pleasurable reading for all those interested in the progress of forestry conservation and development in the Empire. The whole Colony enjoyed good rains, and a record acreage of new plantations, 4429 acres, was made. Excellent growth both of the new and old plantations was recorded, and there were no forest fires of any consequence. The economic slump, as is a common experience in forestry operations, resulted in a considerable drop in the revenue from timber and from the sale of young trees and seeds. For the first time the revenue from firewood actually exceeded that from timber. This factor alone would justify the far-seeing policy of the Colony's administrators in supporting a correct forest administration. It is of interest to note that the management of the intensively worked forests of the Nairobi District was placed on $a_{0}$ satisfactory basis during the year by the completion of detailed working plans. The Chinese tung oil tree, Aleurites Fordii, has been previously alluded to in NATURE, and it was mentioned at the time that experiments were being carried out to ascertain the possibilities of growing the tree commercially in several of the Colonies. Great interest is being shown in this tree by farmers in Kenya, and the Forest Department has acted as agent in the distribution of the seed. A fow experimental trees have been planted, since it was first grown in the Department's arboretum in 1922, at practically every forest station, to test the suitability of the various districts, but the trees are as yet too young to give definite indications.

\section{A Modern Telephone Cable}

IN January 1931 a telephone service was inaugurated over a new submarine cable spanning the hundred miles between Key West, United States, and Havana, Cuba. The new eable is the longest deep-sea telephone cable in the world, and it is unique in having neither intermediate repeaters nor inductive loading. A paper describing its engineering characteristics was read by H. A. Affel, W. S. Gorton, and R. W. Chesnut at the winter convention, held in January, of the American Institute of Electrical Engineers. 'The new cable can operate at a frequency of 28,000 cycles a second, which is about eight times faster than ordinary cables. The feature of the new cable which has made this great improvement possible is the use of paragutta, the new insulating material invented at the Bell Telephone Laboratories. There are three telephone channels in the cable, obtained by an adaptation of the ordinary carrier apparatus used for long distance transmission over open wire lines. There are six frequency bands, one for each direction in the three channels. The largest skin effect occurs in the central conductors, but the effect is also noticeable in the thin return copper tapes. Elaborate precautions were taken to prevent 'noise' intruding in the speech circuit. Frequency limiting filters were introduced into several neighbouring circuits and proved effective. If traffic requirements grow so that more facilities are required, a higher frequency range can be employed 